\title{
Influence of human capital on the level of innovation activity of an enterprise
}

\author{
Natalia Ershova ${ }^{1, *}$, Olga Yutkina $^{1}$, Aleksey Pashkov $^{2}$, Maria Ivanova $^{3}$ and Alena \\ Chistyakova $^{4}$ \\ ${ }^{1}$ Russian State University of Justice, 69, Novocheremushkinskaya street, 117418, Moscow, Russia \\ ${ }^{2}$ Moscow State University of Civil Engineering, 26, Yaroslavskoe sh., 129337, Moscow, Russia \\ ${ }^{3}$ St. Petersburg state University of civil aviation, 38, Pilotov str., 196210, St. Petersburg, Russia \\ ${ }^{4}$ Sankt-Petersburg State Economic University, 21, Sadovaya street, St. Petersburg, 191023, Russia
}

\begin{abstract}
The purpose of this study is to develop an integrated model for stimulating the innovation activity of an enterprise, based on mechanisms to enhance its structural components: intellectuality, innovation and innovativeness. As a result of the study, a mechanism has been created to increase the level of intellectuality of the enterprise due to the development of human capital. This method contains a set of measures aimed at stimulating innovation activity in terms of increasing the number and quality of intellectual projects and developments of employees of the company, responsible for generating innovative ideas.
\end{abstract}

\section{Introduction}

Innovation activity is an important strategic characteristic of any modern enterprise, since it determines the intensity of its innovation activity, i.e. the dynamics of the enterprise's actions to create innovation products, to introduce it into production, and practical implementation. High innovation activity is the main factor of the enterprise, which influences the formation of strategic competitive advantages and the strengthening of positions in the market. The dependence here is directly proportional: the higher the index of innovation activity, the more promising the enterprise and its activities. Thus, innovation activity is an important management tool for achieving high-performance activities of the enterprise.

It is important to understand the interrelationship of the main categories related to innovation, for example, innovative capacity, innovation climate, and innovation activity. Innovative capacity is a set of resources of all kinds, including the material and production, intellectual, scientific and technical, and other necessary for the implementation of innovation activities related to the receipt and implementation of innovations. The capacity initiates and provides the necessary resources to the innovation activity of the enterprise.

\footnotetext{
* Corresponding author: 5880972@mail.ru
} 


\section{Materials and methods}

The organizational structure of the enterprise conducting its own research includes scientific, engineering, design, technological, and information units. Employees of such units will be the objects of influence in order to increase the level of intellectuality of the enterprise. The mechanism for raising the level of intellectuality is shown in Figure 1. This mechanism takes into account the development by each of the components of human capital identified in its structure for the purposes of this study.

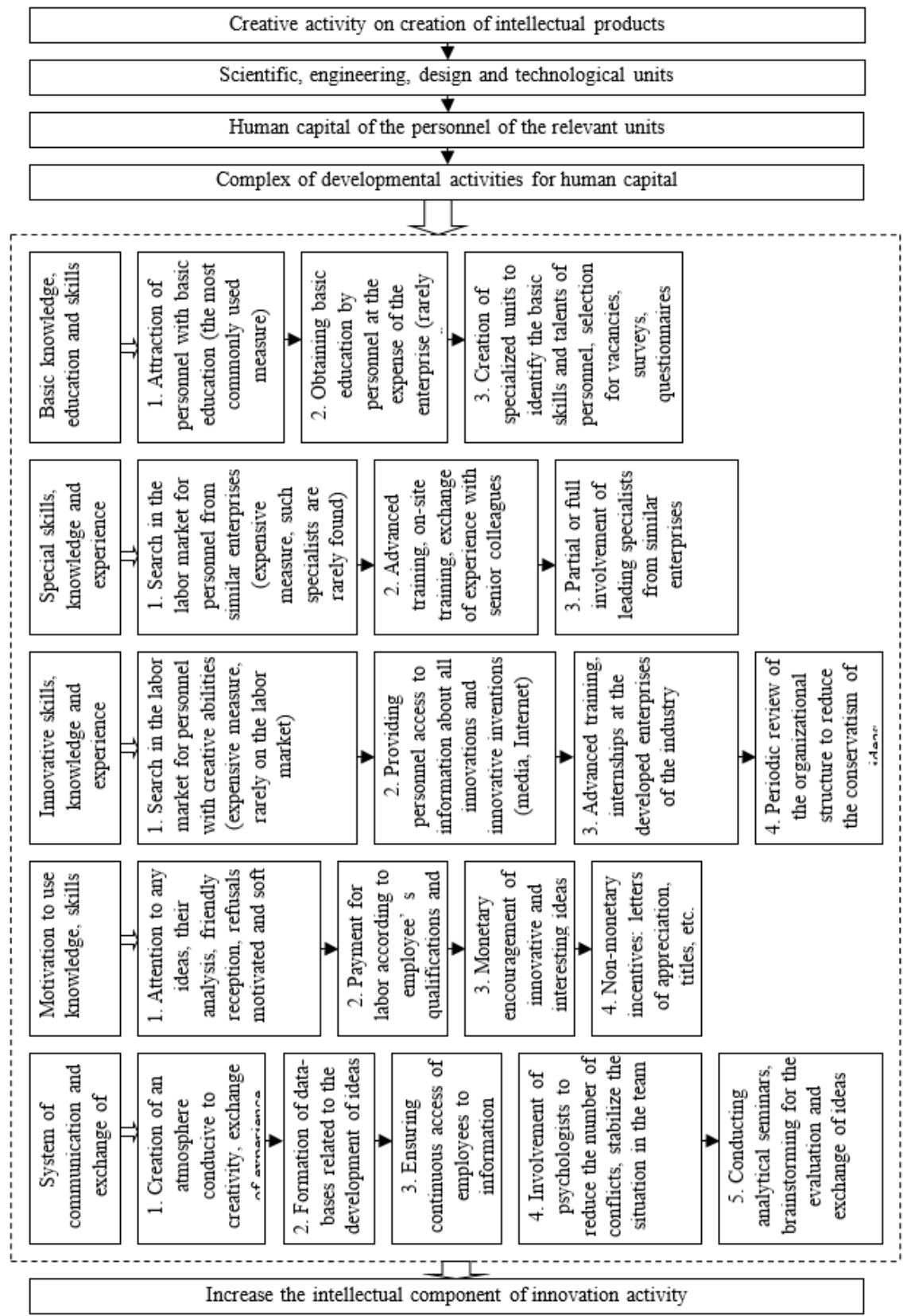

Fig. 1. The mechanism of increasing the intellectuality of an enterprise. 
In modern conditions, the competitiveness of an enterprise directly depends on the quantity, quality and success of innovations introduced, as well as on the continuity of innovation activity, the absence of long stops in innovative development. The desire for the regular creation and implementation of innovations is evidence of active innovation activity and a high level of innovation.

The main impact on human capital in raising the level of innovation should be given to management and production units that must ensure the necessary speed of introduction of innovation, a reduction in the level of rejection, an increase in the labor productivity, clear control over production, and effective marketing when bringing the product to the market for maximum profit. It is important not just to translate the intellectual idea of innovation into action, but to do it as quickly and clearly as possible, beating competitors and securing long-term advantages over them. The developed mechanism of investing funds in the development of human capital in order to increase innovation is shown in Figure 2.

The measures envisaged in the mechanism encourage management personnel to more thoroughly analyze the innovation project, all the risks and benefits that it gives. They will allow developing effective mechanisms of production control and strategies for putting the product on the market for the purpose of selling it, and also analyzing the response of customers and constantly improving products depending on the wishes of consumers, systematically studying the market and the activities of competitors.

Production units will be able to quickly introduce and master an innovation product, will have the abilities and skills developed during training and internships, motivation for their application and sufficient level of communication to quickly exchange experience and information during the production of the product. This will lead to an increase in the quantity and quality of innovations being introduced and mastered, a reduction in the rejection, an increase in labor productivity, and an increase in the innovation activity of the personnel and the enterprise.

Most enterprises that carry out innovative transformations face certain technological, organizational and psychological difficulties. First of all, we are talking about the attitude to the changes being made, the difficulties associated with the perception of new technologies being introduced, especially if they require a long and complex retraining without a special interest and incentive. Misunderstanding of innovative transformations leads to a lack of desire to implement them and sometimes to complete confrontation, rejection of changes.

Every employee involved in innovation activity refers subjectively and evaluates it from the standpoint of how much these changes are clear to him, how useful to him are the consequences that one should expect from the introduction of innovations. If the changes are perceived as illogical, inappropriate and opaque, then they cause panic and fear among the personnel. Usually, the higher the level of novelty of the produced changes, the more doubts and fears they cause.

In the literature, in this context, the Wundt curve is often given, which characterizes the attitude of innovation and its perception by the personnel of the enterprise. If the changes have an insignificant level of novelty, then they are perceived practically indifferent. There is a certain threshold of perception, the overcoming of which will make it possible to show interest. The higher the degree of perceived and understandable to the personnel novelty, the more interest it evokes. 


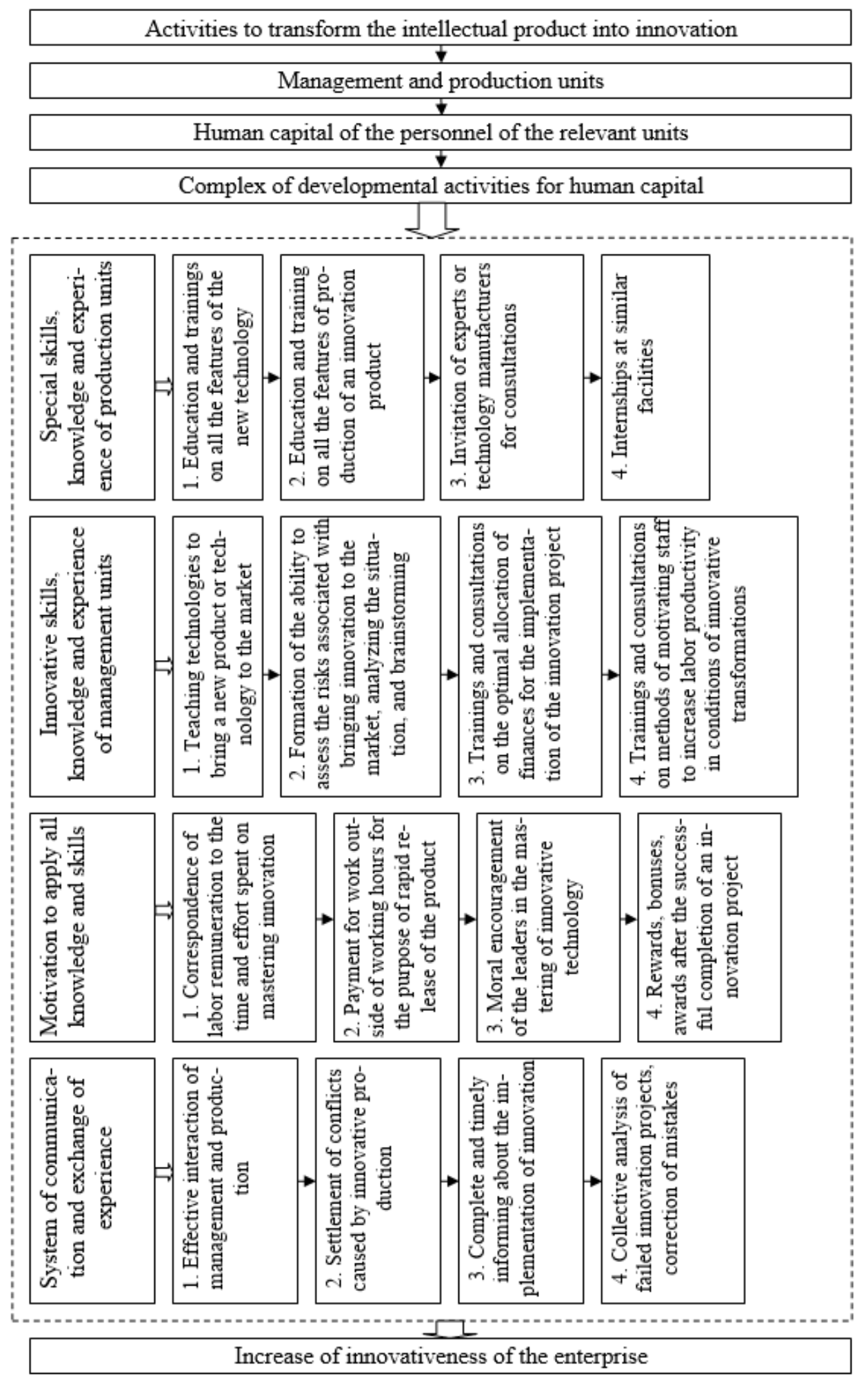

Fig. 2. The mechanism of increasing the innovativeness of the enterprise. 
As a result of the above, seven basic approaches to reducing resistance have been proposed, each of which contains certain procedures and measures (Figure 3).

\begin{tabular}{|c|}
\hline Information approach \\
$\begin{array}{c}\text { Providing access to all } \\
\text { information on the } \\
\text { innovation being } \\
\text { introduced or being } \\
\text { developed }\end{array}$ \\
Full information about \\
possible problems and \\
innovation \\
Formation of a database of \\
knowledge and processes \\
related to the introduction \\
and development of \\
innovation \\
-
\end{tabular}

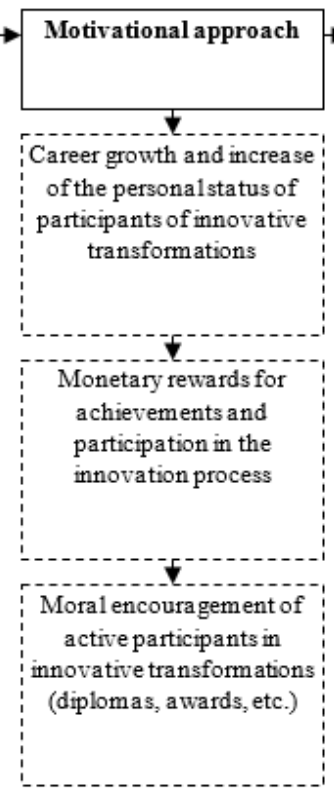

\begin{tabular}{|c|}
\hline $\begin{array}{c}\text { Decrease in personnel } \\
\text { resistance to innovation }\end{array}$ \\
\hline $\begin{array}{c}\text { Increasing } \\
\text { innovativeness of an } \\
\text { enterprise }\end{array}$ \\
\hline $\begin{array}{c}\text { Stimulation of } \\
\text { innovation activity of } \\
\text { an enterprise }\end{array}$ \\
\hline
\end{tabular}
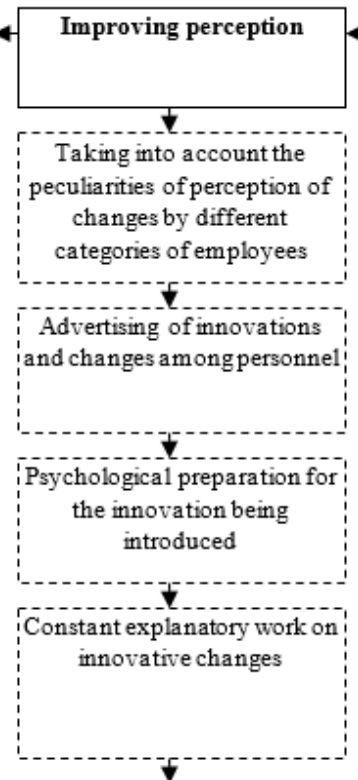

Ensuring maximum convenience of changes for personnel

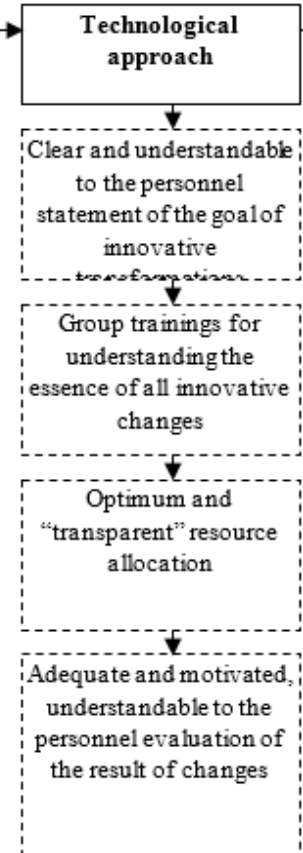

Resource approach

Allocation of additional resources for innovative changes

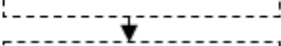

Allocation of resources to counteract innovative risks

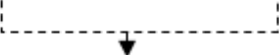

Allocation of resources

for investment in human capital(advanced training, education, internship at the

advanced enterprises of the industry)

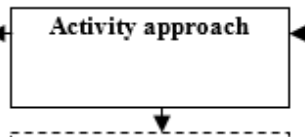

Ethical approach

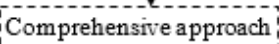
to innovation activity

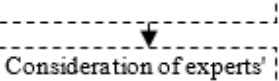

Consideration of experts opinions on issues of innovative

transformations
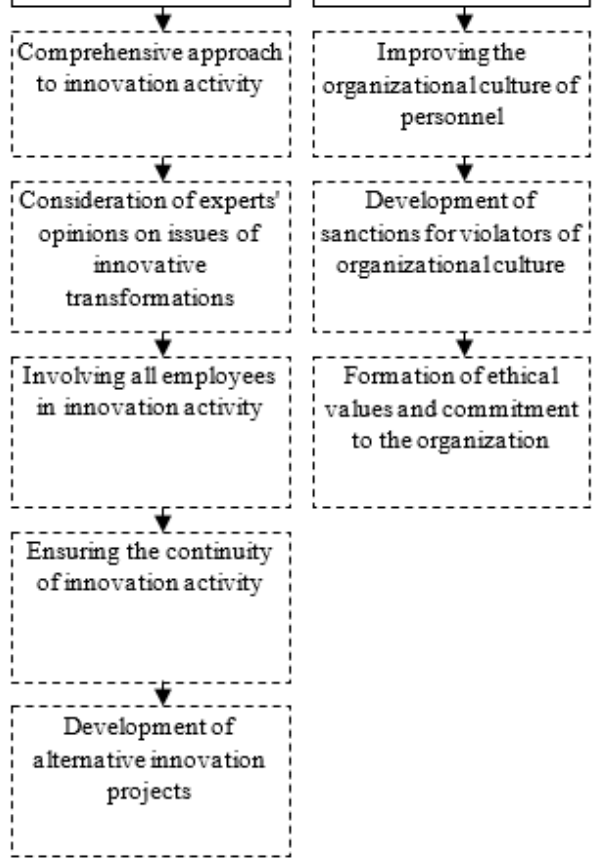

Fig. 3. The mechanism of reducing personnel resistance to innovative transformations for the growth of innovativeness. 
Managers of enterprises can combine them, implementing in a certain sequence to achieve maximum incentive to implement innovation activity. The complex of presented measures will reduce personnel resistance to innovation at the enterprise, increase the level of interest of the enterprise personnel in innovation and the value of its human capital, which ultimately leads to an increase in its level of innovativeness and stimulates innovation activity.

Thus, the innovation activity under the study consists of three components, each of which can be increased by a specific set of activities proposed by us. It is necessary to form an integrated approach to stimulating innovation activity, taking into account developments for each of its components.

As a result of full or partial implementation of the above-mentioned complexes of measures, a positive effect should appear in the form of an increase in the number and quality of intellectual ideas and products, an increase in the rate of development and introduction of innovations, their effectiveness, an increase in sales and commercialization, and a reduction in personnel resistance to innovative changes. This will lead to an increase in the level of intellectuality, innovation and innovativeness of the enterprise - the components of innovation activity.

\section{Results}

Thus, the stimulation of the innovation activity of the enterprise should be carried out in a complex in all areas of innovation activity. In the process of stimulating the activities of individual units without the formation of a single integrated model, any, even the best projected, innovation project risks becoming inefficient and unprofitable. The complex model is formed and shown in Figure 4.

To analyze the effectiveness of the mechanisms and approaches proposed in the study, it is necessary to propose a system for assessing the innovation activity of the personnel before implementing the proposed measures to increase it and after their implementation.

First of all, we will propose approaches to the assessment of the innovation activity of an enterprise, based on those parameters that we proposed as its components.

Innovation activity Ia consists of three components, which we denote respectively: I1 intelligence; I2 - innovation; I3 - innovativeness. If each component has the same value for innovation activity, then formula (1) is applicable for its assessment.

$$
I_{a}=\frac{I_{1}+I_{2}+I_{3}}{3}
$$

Each component, in turn, consists of the individual elements associated with human capital. Intellectuality is measured by the formula (2), which is used for engineering, design and research units of the enterprise, responsible for innovative ideas.

$$
I_{1}=\sum_{j=1}^{5} \frac{I_{1 j}}{5}
$$

$I_{11}$ - basic knowledge of personnel, level of education and its quality;

$I_{12}$ - special knowledge and skills of personnel, accumulated experience;

$I_{13}$ - innovative knowledge and skills, knowledge of innovative technologies;

$I_{14}$ - the level of personnel motivation to generate innovative ideas;

$I_{15}$ - availability and level of development of the communications system at the enterprise. 


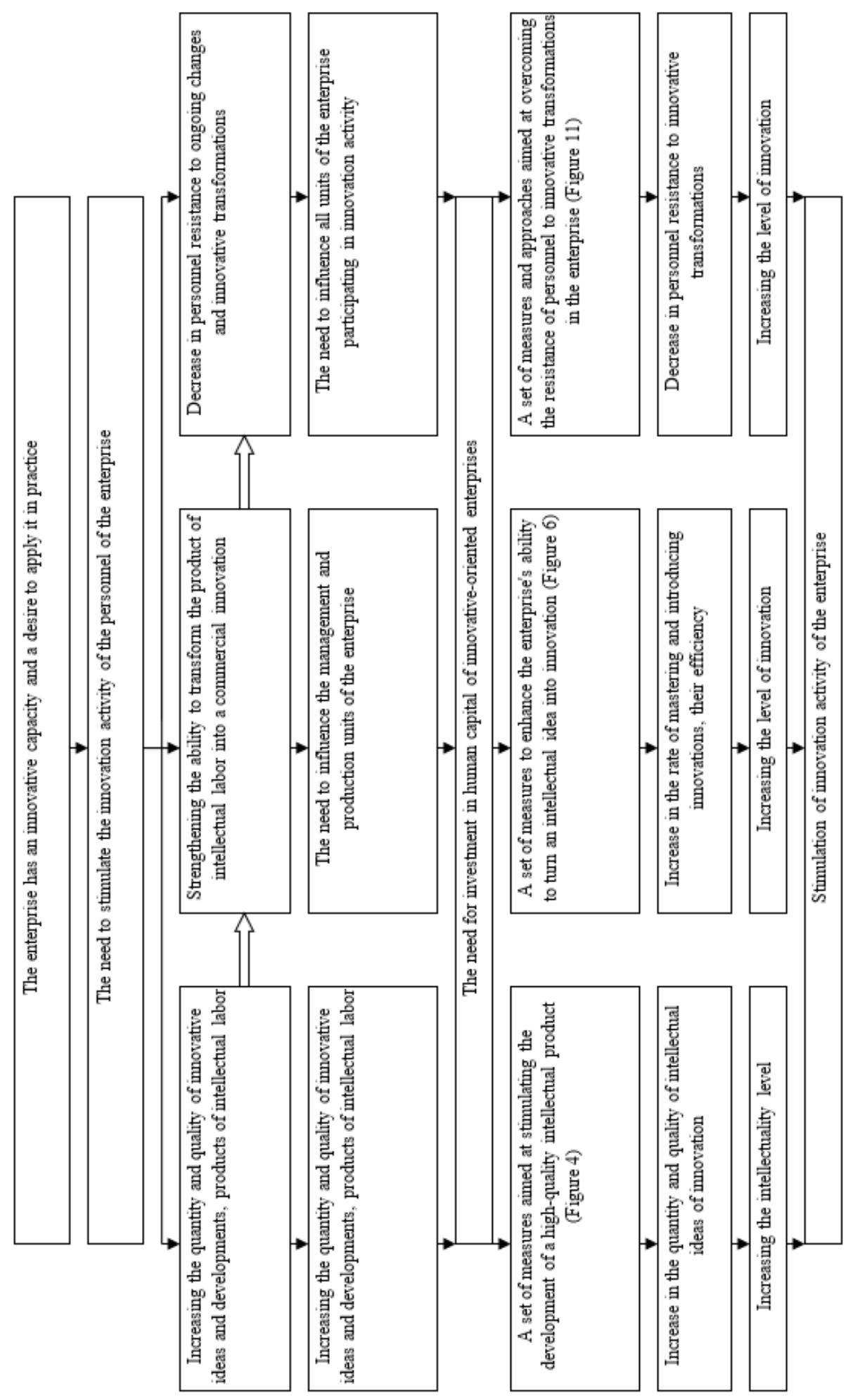

Fig. 4. Integrated model of stimulation of innovation activity of the enterprise. 
As any qualitative parameter, the evaluation of these components is possible only by an expert way. The expert group can include the managers and owners of the enterprise who are interested in evaluating their personnel. You can also involve personnel in selfevaluation, as this will reveal their own idea of abilities, experience and knowledge. It is necessary to involve experts engaged in similar activities, and for the most accurate result, experts in the field of personnel evaluation.

The second component of innovation activity - innovativeness, can also be presented as the sum of individual components (3), which are evaluated for production, management and marketing units that affect the quality and speed of product release, the success of sales:

$$
I_{2}=\sum_{j=1}^{5} \frac{I_{2 j}}{5}
$$

$I_{21}$ - the level of basic knowledge and skills;

$I_{22}$ - characterizes the level of special knowledge and experience;

$I_{23}$ - the level of innovative knowledge and skills needed to turn an idea into innovation;

$I_{24}$ - the level of personnel motivation for the implementation of intellectual ideas and the successful sale of an innovation product;

$I_{25}$ - availability and level of development of the communication system and exchange of experience to turn the intellectual ideas into the end innovation product.

Finally, the third component $I_{3}$ characterizes the level of innovation, i.e. how positively personnel perceive the introduced innovations and the level of rejection of changes, resistance to innovation. We will not divide this component into components, it needs to be assessed by how loyal the personnel is to changes, whether they will lead to significant negative consequences for the personnel, whether people in general understand the basic idea of innovative transformation. This component is assessed for all units of the enterprise.

\section{Conclusion}

The developed integrated model of stimulation of innovation activity of the enterprise allows showing influence of human capital on components of innovation activity. Moreover, the effectiveness of the implementation of intellectual ideas, their introduction into production, and entering the market characterize the level of innovation of the enterprise, including through the development of human capital.

\section{References}

1. J. Shaoul, Critical Perspectives on Accounting 16-4, 441-471 (2005)

2. C. Delmastro, E. Lavagno, L. Schranz, Tunnelling and Underground Space Technology 55, 103-111 (2016)

3. V. Khmel, S. Zhao, IATSS Research 39-2, 138-145 (2016)

4. E. Chirkunova, E. Kireeva, A. Kornilova, J. Pschenichnikova, Procedia Engineering 153, 112-117 (2016)

5. M. Dudi, N. Vatin, Y. Barabanshchikov, Magazine of Civil Engineering 54(2), 33-45 (2015)

6. P. Bellagente, F. Bonafini, C. Crema, A. Depari, P. Ferrari, A. Flammini, G. Lenzi, M. Pasetti, S. Rinaldi, E. Sisinni, 2018 IEEE International Workshop on Metrology for Industry 4.0 \& IoT, Brescia, Italy (2018). DOI: 10.1109/METROI4.2018.8439039 
7. I. Hirkovskis, D. Serdjuks, V. Goremikins, L. Pakrastins, N. Vatin, Magazine of Civil Engineering 57(5), 86-96 (2015)

8. A. Lukmanova, M. Mishlanova, International Journal of Economics and Financial Issues 5, 208-216 (2012) 